\title{
THE EFFECT OF EX-SITU STEAM TREATMENT ON AN AMORPHOUS CARBON FILM WITH AU ISLANDS
}

\author{
C.E. Kliewer and D.L. Dorset \\ ExxonMobil Research \& Engineering, Rte 22 East, Annandale, NJ 08801
}

Obtaining morphological and chemical information under industrially relevant conditions remains an important aspect of materials characterization. To better understand the structural and chemical properties of our materials, a variety of ex-situ TEM protocols have been developed ${ }^{1-2}$ yielding interesting results in supported metal studies. ${ }^{3-5}$

ExxonMobil's dedicated ex-situ reactor is equipped not only with reducing and oxidizing gas feed manifolds but also with a liquid feed line. Liquid feed, delivered via an ISCO pumping system, gives us significant additional flexibility and more closely approximates actual process conditions when treating materials. In this study, the ISCO pumping system was used to examine the effect of steam treatment on an amorphous carbon film with and without deposited $\mathrm{Au}$ islands.

Initially, an amorphous carbon film was examined in the TEM. No changes in the film were observed after an ex-situ Ar treatment at $150^{\circ} \mathrm{C}$ and $1 \mathrm{~atm}$. for $30 \mathrm{~min}$. (Fig. 1a-1b). The same treatment was repeated with an Ar/steam (1:1) $\mathrm{mix}$ at $150^{\circ} \mathrm{C}$ and $1 \mathrm{~atm}$. for $30 \mathrm{~min}$.; no morphological changes were observed in the film (Fig. 1c). However, when Au islands were deposited on an amorphous carbon film, and it was treated as described above; significant changes were observed (Fig. 1d-1f). While the Au islands themselves were not greatly affected by either the thermal or steam treatments, the structure of the carbon film was altered. In the presence of steam, the Au served as a catalyst rearranging the amorphous carbon to a more graphitic form; these data suggest a role of metal in the crystallization of carbon.

References:

1. L.F.Allard et. al., Proc Microsc. Microanal. 3 Suppl 2 (1977) 595

2. C.E.Kliewer et. al., Proc Microsc. Microanal. 5 Suppl 2 (1999) 926

3. C.E.Kliewer et. al., Proc Microsc. Microanal. 6 Suppl 2 (2000) 378

4. C.E.Kliewer et. al., Proc Microsc. Microanal. 7 Suppl 2 (2001) 1214

5. C.E.Kliewer et. al., Proc Microsc. Microanal. 8 Suppl 2 (2002) 1408CD 


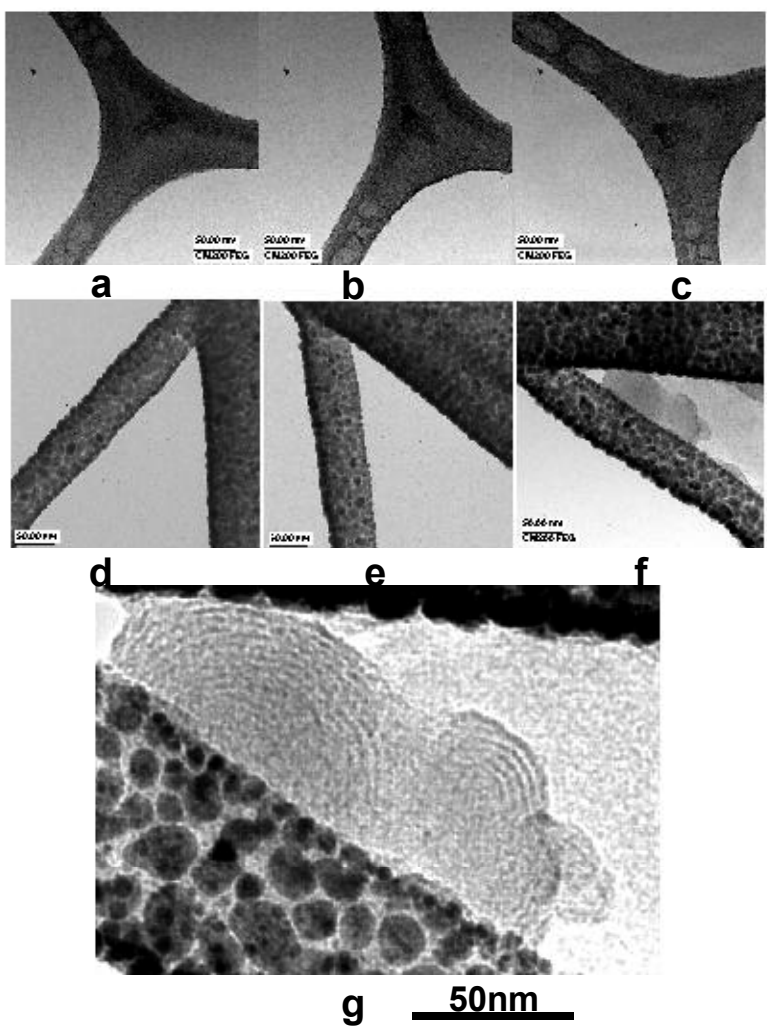

Figure 1: (a) Holey carbon film; (b) area (a) after $150^{\circ} \mathrm{C}, 30 \mathrm{~min}$. $\mathrm{Ar}$ treat; (c) area (b) after $\mathrm{Ar} / \mathrm{steam}(1: 1)$ at $150^{\circ} \mathrm{C}$ for 30 min.; (d) $\mathrm{Au}$ islands on holey carbon film; (e) area (d) after $150^{\circ} \mathrm{C}, 30 \mathrm{~min}$. Ar treat; (f) area (e) after $\mathrm{Ar} / \mathrm{steam}(1: 1)$ at $150^{\circ} \mathrm{C}$ for 30 min.; and (g) enlargement of area (f). 